\title{
O MEDO NA APRENDIZAGEM DA NATAÇÃO
}

\author{
Aline Dessupoio Chaves \\ Universidade Federal do Triângulo Mineiro, Minas Gerais, Uberaba, Brasil \\ Alexandre de Carvalho Silva \\ Universidade Federal do Triângulo Mineiro, Minas Gerais, Uberaba, Brasil \\ Osvaldo Luiz Ferraz \\ Universidade de São Paulo, São Paulo, São Paulo, Brasil \\ Myrian Nunomura \\ Universidade de São Paulo, São Paulo, Ribeirão Preto, Brasil \\ Michele Viviene Carbinatto \\ Universidade de São Paulo, São Paulo, São Paulo, Brasil
}

\begin{abstract}
Resumo
O objetivo deste estudo foi verificar o que causa medo nos praticantes de natação e identificar o que eles fazem para superar esse sentimento. A amostra foi composta por 18 alunos já iniciados na natação, com média de idade de 29,72 \pm 9,70 anos. O instrumento utilizado foi um questionário e para análise dos dados foi utilizada a estatística descritiva, e o método do "Discurso do Sujeito Coletivo" (DSC). Identificou-se que a imersão, a saída (mergulho), a falta de prática e os traumas, causam medo em alguns alunos. Para superar o medo, realizam técnicas de respiração e tentam executar o movimento que sentem medo. Compreender o medo do aluno pode auxiliar aos profissionais no estabelecimento de direcionamentos didáticos para a aprendizagem da natação.
\end{abstract}

Palavras-chave: Medo. Natação. Aprendizagem.

\section{Introdução}

A natação é uma atividade tão antiga quanto o homem, que se desloca no meio líquido, das mais variadas formas e direcionado aos mais diversos objetivos. Com o surgimento das aulas de natação e a sua organização por se tratar de um esporte, ampliou-se, significativamente, o interesse em estudos sobre a sistematização do ensino dos nados, o treinamento do nadador, bem como a adaptação do praticante ao meio líquido.

A natação, como prática esportiva, também foi beneficiada pelos conhecimentos divulgados e ampliados pelas Ciências do Esporte (CE) que se desenvolve e se beneficia pela interdisciplinaridade (TANI; BENTO; PETERSEN, 2006; BENTO; TANI; PRISTA, 2010).

As discussões na CE suscitaram defesas de que o praticante é um ser múltiplo e complexo, e que as dimensões sociais, biológicas, psicológicas e históricas interferem, diretamente, no processo de ensino e aprendizagem no esporte e, por sua vez, na formação esportiva a longo prazo (NISTA-PICCOLO; NUNOMURA, 2014; GAYA; MARQUES; TANI, 2004). E, neste sentido, a atuação do profissional deve ser direcionada para atender aos 
interesses e necessidades de cada praticante e em cada uma dessas dimensões.

Nas aulas de natação notamos que após um período de adaptação ao meio líquido alguns alunos demonstram dificuldades na aprendizagem de habilidades básicas da modalidade e o fator emocional parece ser um dos desencadeadores dessa dificuldade, dos quais destacamos o "medo", que é uma das emoções mais estudadas por ser uma emoção cognitivo-reativa, associada aos mecanismos de sobrevivência, e no caso da aprendizagem da natação pode gerar bloqueio ou atrasos na evolução do aluno, levando até ao abandono em algumas situações.

Para compreender a influência do aspecto psicológico na aprendizagem é necessária a compreensão das emoções, classificadas como primárias, aquelas vivenciadas na infância; e secundárias, as experiências na vida adulta, que se somam às emoções ora vivenciadas (DAMÁSIO, 1996).

Lent (2001) classifica as emoções em: positivas (que provocam prazer); negativas (que provocam desprazer); pares de emoções opostas (alegria e tristeza); e experiências únicas (desprezo). E, apoiado na neurobiologia, relata que as emoções negativas são mais conhecidas do que as positivas.

Sentir emoções nos esportes parece algo muito comum e essas estão intrinsecamente relacionadas a cada pessoa, pois podem ser desencadeadas por diversos fatores e influenciadas por histórias vividas diferentes.

Thomas (1983) relata que é comum notar a sensação do medo entre os esportistas iniciantes, devido à vivência de movimentos novos, ou ainda, à realização desses em meio estranho ao cotidiano do ser humano, fato que pode dificultar a orientação espacial e o equilíbrio.

A partir da incorporação e da sensibilização corporal aos gestos esportivos da modalidade praticada, o medo tenderia a diminuir. Assim, o profissional deve ter atenção e direcionar a prática para atender aos momentos distintos da aprendizagem vinculados às diferentes sensações de medo do aluno.

É frequente depararmos com pessoas que buscam a natação para superarem sentimentos negativos, como o medo da água. Nessa perspectiva, alguns indivíduos acabam temendo o pior, antes mesmo da execução de alguma tarefa, impedindo-o de experimentar. Esse sentimento pode estar relacionado com as vivências anteriores que não tiveram êxito na execução, ou ainda, devido a traumas que desencadearam o medo naquela situação.

Desta forma, é necessário investigar o motivo que gerou essa emoção, para que se determine quando o medo é normal ou patológico, e consequentemente, quando a intervenção profissional é necessária.

A palavra medo origina-se do latim metus, que significa temor. A psicologia define o termo como uma série de emoções que se baseiam na percepção, na expectativa ou na imaginação, associadas a um estado de excitação do organismo, que gera uma sensação desagradável ao indivíduo (HUBER, 2000).

Morris e Kratochwell (1983) definem o medo como uma reação emocional mais ou menos intensa perante um perigo específico, real ou imaginário, como o medo de imergir em uma piscina.

De acordo com Holanda et al. (2013), os estímulos ambientais causadores do medo podem ser classificados de duas formas: incondicionados, quando não há a pretensão de causar medo e são, na maioria das vezes, naturais (sons intensos, altura, escuridão); e condicionais, que são possíveis de serem evitados (ir ao dentista ou ao médico; medo de 
cachorro, barata).

Hongler (1988) apresenta o medo como um estado emocional desagradável a quem o sente e aflora quando o indivíduo se encontra em uma situação que ele julga ameaçadora e, portanto, estressante.

Paradoxalmente, o medo também pode ser visto como benéfico à medida que desperta o praticante para riscos em potencial e para prevenção de possíveis acidentes (BROCHADO, 2002). Na natação, o medo no ambiente líquido pode ser considerado positivo no sentido de chamar atenção do nadador sobre riscos inerentes a certas atividades e ao meio.

Assim, é necessário que os professores ensinem novas habilidades para seus alunos, os encorajem para realizá-los, mas é de fundamental importância que os alertem sobre prováveis acidentes, situações de perigo, entre outras informações que visem à segurança do aluno.

Portanto, o medo apresenta uma dupla contrariedade: não o ter suficiente torna a vida muito arriscada, mas em excesso também limita as probabilidades de sobrevivência (FISCHER et al., 2009).

Uma vez que a pessoa aprende a se sentir amedrontada em relação a algo, ela tende a associar um sentimento de pavor a essa experiência, que ficou armazenada na memória. $\mathrm{O}$ contrário também pode ocorrer, ou seja, ao aprender a controlar esse sentimento, ela saberá como reagir quando situações semelhantes acontecerem.

É função do professor desenvolver meios para controlar esse processo emocional com seus alunos (por meio de orientação e informações, relaxamento etc.); estimulá-lo a enfrentar esse sentimento (pontuando os riscos reais) de forma progressiva e a voltar às origens dessa emoção para que o medo possa ser compreendido e controlado.

Porém, muitos adultos sentem-se constrangidos e escondem o sentimento de medo do professor quando estão aprendendo uma habilidade nova, especialmente, pelo receio em serem vistos como fracos e tolos (FEIGLEY, 1987). Ekman (2004) assegura que é possível identificar o medo por meio da leitura da expressão facial da pessoa, ou como ela se sente ou como ela gostaria que os outros pensassem como ela se sente. $\mathrm{O}$ mesmo acontece com os movimentos e as posturas corporais que tendem ser mais rígidos em situações de medo.

Embora alguns estudos tenham investigado o medo em praticantes de natação, nenhum pesquisou a causa do medo e como os alunos fazem para superá-lo (GRAHAN; GAFFAN, 1997; PARKER; BLANKSBY, 1997; WEISS et al., 1998; POULTON et al., 1999).

No estudo de Grahan e Gaffan (1997) foram investigados alunos iniciantes de natação, crianças e adultos, e verificou-se que o medo das crianças está relacionado ao desconhecido enquanto dos adultos com situações vivenciadas.

Parker e Blanksby (1997) investigaram crianças de dois a sete anos com o objetivo de determinar quando acontece a confiança na aprendizagem das habilidades básicas da natação. Aos quatro anos de idade, as crianças demonstraram a capacidade para atingir os níveis de confiança de água e habilidades básicas de locomoção.

Weiss et al. (1998) pesquisaram crianças com idade média de 6,2 anos que foram identificadas com medo de água e submetidas nas aulas de natação a modelos de enfrentamento e autoeficácia, encontrando resultados que sugeriram que uma intervenção de modelagem combinada com aulas de natação é um agente mais eficaz de mudança de comportamento para as crianças com medo.

Poulton et al. (1999) analisaram a relação entre trauma de água e habilidades aquáticas antes da idade de nove anos e a presença do medo e fobia de água aos 18 anos, porém não encontraram nenhuma evidência dessas relações. 
Na literatura nacional, o estudo de Ressurreição et al. (2008) com crianças com Síndrome de Down e o de Cavalcanti e Barbosa (2013) que investigou idosos, ambos com sujeitos praticantes de natação, mostraram que o medo é uma emoção presente na aprendizagem da modalidade para alguns alunos. Além disso, encontramos uma pesquisa que cita o medo como um dos motivos que levou à prática da natação, como forma de superação e enfrentamento (MINEIRO et al., 2013).

Os resultados dos estudos demonstram a necessidade de investigar os aspectos relacionados ao medo que influenciam nessa prática e compreender os seus motivos originais. Dessa forma, o professor poderá tornar a prática mais prazerosa e auxiliar o aluno a lidar com essa emoção.

Assim, o objetivo deste estudo é verificar o que causa medo nos alunos já iniciados na natação e identificar o que eles fazem para superar esse sentimento.

\section{Métodos}

Trata-se de uma pesquisa de caráter exploratório-descritivo, que foi submetido e aprovado pelo Comitê de Ética e Pesquisa (CEP) da Universidade Federal do Triângulo Mineiro de acordo com o protocolo $\mathrm{n}^{\mathrm{o}} 2661$.

A amostra foi composta por 18 alunos de natação, com idade acima de 18 anos, de ambos os sexos, que estavam na fase de aprendizagem dos nados, praticantes há mais de um ano da modalidade, e que, na primeira sessão, relataram ao professor que sentiram medo em algum momento durante a aula.

Antes de assinarem o termo de consentimento livre e esclarecido (TCLE), todos os voluntários foram informados dos procedimentos metodológicos da pesquisa, incluindo riscos e benefícios do estudo.

O instrumento utilizado para a coleta dos dados foi um questionário, que primeiramente registrou o perfil do aluno, em relação à idade e o sexo; e, posteriormente, foi composto por sete perguntas, sendo duas questões fechadas e cinco questões abertas relacionadas ao medo na prática da natação.

A pesquisa foi realizada em escolas de natação na cidade de Uberaba - MG. O pesquisador entregou o questionário ao aluno que o preencheu individualmente. Para análise dos dados quantitativos como idade, sexo e perguntas fechadas foi utilizada a estatística descritiva, por meio da média e desvio padrão, e para as questões abertas aplicou-se o método do "Discurso do Sujeito Coletivo" (DSC) de Lefévre; Lefèvre (2003), que permite uma análise qualitativa dos dados.

Para organizar os DSCs, Lefévre e Lefèvre (2003) criaram as seguintes figuras metodológicas: Expressões-chave $(\mathrm{ECH})$ : pedaços, trechos ou transcrições literais do discurso, demarcadas pelo pesquisador (sublinhadas, iluminadas, coloridas); Ideias centrais (IC): é um nome ou expressão linguística que revela e descreve, de forma sintética, precisa e fidedigna, o sentido de cada um dos discursos analisados; Discurso do Sujeito Coletivo (DSC): é um discurso síntese redigido na primeira pessoa do singular e composto pelas ECH que têm a mesma IC.

$\mathrm{Na}$ categorização das respostas, utilizou-se como IC expressões relacionadas à resposta dos sujeitos e aos termos já destacados na literatura. Após isso, calculou-se a frequência de respostas de cada questão. 


\section{Resultados}

Ao traçar o perfil dos alunos analisados, constatou-se que a média de idade foi de $29,72 \pm 9,70$ anos, sendo oito pessoas do sexo masculino e dez do feminino. O tempo de prática da modalidade variou de um a cinco anos.

O questionário continha uma questão fechada para verificar se os praticantes, que manifestavam medo, conseguiam se deslocar no meio líquido, e todos os participantes responderam que sim.

A primeira pergunta aberta referia-se ao sentimento do aluno ao entrar na piscina, cujos resultados estão demonstrados no Quadro 1, no qual ( $\mathrm{A}=$ Amostra, $\mathrm{F}=$ feminino e $\mathrm{M}=$ masculino) e o número antecedendo o sexo equivale à identificação do participante.

\section{Quadro 1- Sentimentos ao entrar na piscina}

\begin{tabular}{|l|l|l|}
\hline Ideias Centrais & Amostra & Expressões-chave \\
\hline Estado de alerta & $\mathrm{n}=1$ & A1M: "Normal, apenas fico mais atento". \\
\hline Nada & $\mathrm{n}=3$ & $\begin{array}{l}\text { A4M: "Nada específico". } \\
\text { A18F: "Quando conheço a piscina não sinto } \\
\text { nada" }\end{array}$ \\
\hline Aspectos psicológicos positivos & $\mathrm{n}=5$ & $\begin{array}{l}\text { A5M: "Tenho vontade de mergulhar" } \\
\text { A14F: "Vontade de aprender todos os } \\
\text { métodos de nado" } \\
\text { A15F: "Uma sensação boa" }\end{array}$ \\
\hline Aspectos psicológicos negativos & $\mathrm{n}=9$ & $\begin{array}{l}\text { A7M: "Ansiedade e nervosismo". } \\
\text { A14F: "Ainda sinto um pouco de medo. No } \\
\text { início há } \pm 4,5 \text { anos não entrava na piscina } \\
\text { sem ajuda de alguém". }\end{array}$ \\
\hline
\end{tabular}

Ao questionar se o aluno sente medo ao entrar na piscina, sete praticantes disseram que não e 11 participantes que sim.

Dentre os sete praticantes que relataram não sentir medo, um deles relatou que o gosto pela prática de esportes aquáticos elimina esse sentimento. Por sua vez, no Quadro 2 apontamos os sentimentos de medo elencados pelos demais sujeitos.

\section{Quadro 2- Sentimento de medo ao entrar na piscina}

\begin{tabular}{|l|l|l|}
\hline Ideias Centrais & Amostra & Expressões-chave \\
\hline $\begin{array}{l}\text { Fatores Psicológicos Negativos } \\
\text { (sente medo) }\end{array}$ & A4M: "Tenho medo de escorregar na \\
& & $\begin{array}{l}\text { borda" } \\
\text { A9F: "Dependendo da profundidade da } \\
\text { piscina tenho medo de me afogar" } \\
\text { A11F: "Quando era criança cai na } \\
\text { borda da piscina e levei 3 pontos no } \\
\text { rosto". }\end{array}$ \\
\hline
\end{tabular}

A terceira questão aberta investigou se o aluno sente medo em realizar algum movimento na piscina, e todos os investigados $(n=18)$ relataram que sim. O Quadro 3 
apresenta os movimentos relatados que geram medo.

Quadro 3 - Medo relacionado a algum (s) movimento (s) na piscina

\begin{tabular}{|c|c|c|}
\hline Ideias Centrais & Amostra & Expressões-chave \\
\hline Imersão & $\mathrm{n}=7$ & $\begin{array}{l}\text { A16F: "Qualquer exercício que se tenha que colocar a } \\
\text { cabeça inteira dentro d'água" }\end{array}$ \\
\hline Virada & $\mathrm{n}=4$ & $\begin{array}{l}\text { A6M: "Virada. Tenho medo de bater o pé na borda e medo } \\
\text { de entrar água no nariz". }\end{array}$ \\
\hline Saída (mergulho) & $\mathrm{n}=5$ & A3M: “Sim, virada e a saída”. \\
\hline Nado costas & $\mathrm{n}=3$ & $\begin{array}{l}\text { A10F: "Sim. Nadar de costas, afundar, perder o fôlego e } \\
\text { passar mal". }\end{array}$ \\
\hline $\begin{array}{l}\text { Flutuação e uso de } \\
\text { flutuadores }\end{array}$ & $\mathrm{n}=2$ & $\begin{array}{l}\text { A18F: "Flutuar e mergulhar" } \\
\text { A14F" "[...] o uso de flutuadores }[\ldots] " .\end{array}$ \\
\hline Respiração & $\mathrm{n}=1$ & A17F: "Da respiração do nado crawl" \\
\hline Vários & $\mathrm{n}=2$ & $\begin{array}{l}\text { A12F: "Dependendo da profundidade da piscina, sinto } \\
\text { insegurança em realizar qualquer tipo de movimento" } \\
\text { A14F: "[...] de virar da posição de costas para a outra ou } \\
\text { vice-versa e de pular na piscina" }\end{array}$ \\
\hline
\end{tabular}

Em relação ao que o participante faz para superar o seu respectivo medo, as respostas obtidas estão demonstradas no Quadro 4.

Quadro 4 - Estratégias para superar o medo

\begin{tabular}{|l|l|l|}
\hline Ideias Centrais & Amostra & Expressões-chave \\
\hline Respira mantendo a calma & $\mathrm{n}=7$ & $\begin{array}{l}\text { A12F: "Respiro profundamente, digo para } \\
\text { mim mesma que devo manter a calma e me } \\
\text { concentro no pensamento de que nada irá dar } \\
\text { errado". } \\
\text { A13F: "Uso o método de respiração e tento } \\
\text { buscar a confiança" }\end{array}$ \\
\hline Pensa positivo & $\mathrm{n}=3$ & $\begin{array}{l}\text { A3M: "Tento pensar que tudo vai dar certo" } \\
\text { A10F: "Penso que devo ser corajosa e superar } \\
\text { minhas barreiras" }\end{array}$ \\
\hline Não faz o movimento & $\mathrm{n}=4$ & $\begin{array}{l}\text { A4M: "Não tento fazer, mas fico passando } \\
\text { vontade". } \\
\text { A11F: "Evito olhar e saltar da borda, sempre } \\
\text { entro na piscina pelas escadas" }\end{array}$ \\
\hline Tenta executar o movimento & $\mathrm{n}=5$ & $\begin{array}{l}\text { A14F: "Insisto bastante para executar o } \\
\text { movimento e não desisto" } \\
\text { A8M: "Tento me concentrar no exercício" }\end{array}$ \\
\hline Não pensa no medo & A16F: "Não penso no medo" \\
\hline Não consegue superar & $\mathrm{n}=1$ & $\begin{array}{l}\text { A17F: "Não consigo driblar e acabo fazendo a } \\
\text { respiração errada". }\end{array}$ \\
\hline
\end{tabular}

A última questão aberta referiu-se à causa do medo, no qual sete praticantes relataram 
que o medo foi causado por influência de fatores externos como outra pessoa ou até mesmo a mídia, enquanto nove participantes relataram que o medo está relacionado aos fatores como a inexperiência no meio aquático e traumas, e dois não souberam explicar a resposta. $\mathrm{O}$ Quadro 5 apresenta as causas apontadas pelos sujeitos.

Quadro 5 - Medo com e sem influência externa

\begin{tabular}{|c|c|c|}
\hline Ideias Centrais & Amostra & Expressões-chave \\
\hline \multicolumn{3}{|c|}{ Sem influência externa } \\
\hline Falta de prática & $\mathrm{n}=4$ & $\begin{array}{l}\text { A1M: "[...] pode ser pela falta de prática" } \\
\text { A17F: "Talvez pela falta de experiência pré- } \\
\text { matura" }\end{array}$ \\
\hline Trauma & $\mathrm{n}=4$ & $\begin{array}{l}\text { A2M: "Talvez, mas no meu caso o medo é por um } \\
\text { trauma ocorrido na infância" } \\
\text { A11F: "[...] eu cai sozinha" }\end{array}$ \\
\hline Insegurança & $\mathrm{n}=1$ & A4M: “[...] é pela falta de segurança” \\
\hline \multicolumn{3}{|c|}{ Com influência externa } \\
\hline Reportagens da mídia & $\mathrm{n}=1$ & $\begin{array}{l}\text { A6M: "Talvez por reportagens de } \\
\text { documentários [...]" }\end{array}$ \\
\hline $\begin{array}{l}\text { Casos traumáticos com } \\
\text { família e conhecidos }\end{array}$ & $\mathrm{n}=3$ & $\begin{array}{l}\text { A5M: "[...] porque eu já vi pessoas se machucarem } \\
\text { ao tentar fazer esse salto" }\end{array}$ \\
\hline Trauma & $\mathrm{n}=3$ & $\begin{array}{l}\text { A9F: "Sim, quando criança meu irmão me jogou } \\
\text { várias vezes na piscina" } \\
\text { A10F: "Quando criança minha mãe estava me } \\
\text { ensinando a nadar de costas e eu quase me } \\
\text { afoguei" }\end{array}$ \\
\hline
\end{tabular}

\section{Discussão}

No estudo percebemos que independente do tempo de prática do aluno, seja de um ano ou cinco anos, o medo se apresenta, principalmente, relacionado com alguns movimentos da natação. Nessa perspectiva, Brochado (2002) cita que a diversidade do medo e sua manifestação perpassa todos os níveis de habilidade esportiva, diferindo apenas nos elementos específicos do esporte ou situações em que são apresentadas (uma aula ou competições em nível internacional, por exemplo).

Analisando o Quadro 1, observamos que a maioria $(n=9)$ das pessoas apresenta sentimentos negativos, como insegurança, ansiedade e nervosismo e, principalmente, medo ao entrar na piscina. Em relação aos sentimentos positivos, cinco pessoas responderam que sentem prazer ou uma sensação boa, por outro lado três pessoas responderam que não sentem nada ao entrar na piscina, embora no relato delas tenha ficado claro o sentimento de medo em relação ao ambiente aquático. $\mathrm{O}$ estado de alerta apontado por um sujeito demonstra $\mathrm{o}$ desconforto em estar numa piscina, pois se trata de um aluno que não apresenta domínio do corpo nesse meio.

De acordo com os relatos, observamos que o medo do desconhecido está presente no discurso de um praticante, que mostra a dificuldade sentida quando não conhece a piscina que adentrará. 
Ressalta-se que há diferenças entre estar na terra e na água, por isso há necessidade de realizar uma reaprendizagem postural e motora antes de iniciar a locomoção na água (GALDI et al., 2004).

Velasco (1997) aponta que as propriedades físicas da água como: densidade, empuxo, turbulência, fricção, pressão, velocidade e temperatura, tornam o ambiente aquático um meio "desconhecido" no qual o estar e o agir são diferentes quando ocorrem no meio terrestre.

Alguns praticantes, embora tenham alguma experiência prática, ainda sentem um pouco de medo. Essas pessoas buscam a superação desse sentimento nas aulas e tentam quebrar algumas barreiras ao entrar na piscina, e por isso os conteúdos da natação precisam ser trabalhados com cautela.

No Quadro 2 verificamos que a maioria $(n=11)$ dos entrevistados sente medo ao entrar na piscina. Os fatores psicológicos negativos mais relatados foram: insegurança, medo de escorregar na borda, cair e não conseguir se levantar e afogar.

Essas situações relacionam-se ao que Mira e Lópes (1991) e Cox (1994) apresentam como o medo de causa, medo da contusão e medo do vexame social. Podemos imaginar o constrangimento de um adulto que se afoga num ambiente em que inúmeras pessoas nadam com certa tranquilidade, ou, quando a pessoa cai perante desconhecidos.

É de suma importância que o professor de natação oriente a entrada na piscina para que ocorra em segurança. Inclusive, o fator segurança, quando em falta, é motivo de desistência da prática esportiva, como ocorre em outras modalidades (MAGYAR; CHASE, 1996).

Para aqueles que não têm medo do ambiente aquático, essa preocupação parece irrelevante, mas percebemos na prática que, por vezes, alunos não sabem como se posicionar na escada da piscina para entrar na água, ou por desconhecer a profundidade da piscina, ficam inseguros para se deslocarem nesse ambiente.

Esta situação foi relatada por um dos alunos que afirmou que, dependendo da profundidade da piscina, sente medo de afogar. Segundo Szpilman (2005), geralmente o afogamento está relacionado às atividades de lazer que se transformam em evento dramático, e que a falta de supervisão pode ser considerada um fator de risco para esse acontecimento, pois o fato de saber nadar não é suficiente para evitar acidentes. Muitas vezes o nadador está condicionado a utilizar apenas piscinas rasas e tem dificuldades de se ambientar em maiores profundidades.

Em relação ao Quadro 3, todos os sujeitos disseram ter medo de algum movimento dentro da água. Considerando-se que cada pessoa poderia citar mais de um movimento no qual sente medo, o movimento mais presente nos depoimentos foi a imersão $(n=7)$, seguido da saída (mergulho) $(n=5)$, das viradas $(n=4)$, do nado costas $(n=3)$, da flutuação $(n=2)$ e da respiração $(n=1)$. Foram classificados os participantes que responderam que, dependendo da profundidade, têm medo de realizar vários movimentos $(\mathrm{n}=2)$, e também de mudar da posição de decúbito dorsal para ventral ou vice-versa, habilidade essa que pode estar relacionada à flutuação ou à virada do nado costas.

Com base nessas respostas, constatamos que muitas pessoas, independentemente do tempo de prática, apresentam medo relacionado aos movimentos de adaptação ao meio líquido, como flutuação, imersão e expiração embaixo d’água. Esses conteúdos causam desconforto porque não são naturais aos seres humanos, na verdade são opostos ao que se faz no meio terrestre. Alguns alunos também sentem medo no uso de alguns instrumentos que têm por finalidade facilitar o aprendizado, como é o caso dos flutuadores. 
Fernandes e Costa (2006) consideram que devemos evitar o uso excessivo de aparatos pedagógicos, pois embora auxilie o aluno em relação à postura e ao equilíbrio dinâmico no meio líquido, muitas vezes mascara as percepções do aluno e pode torná-lo dependente do material para se sentir seguro no ambiente.

Algumas pessoas mostram-se apreensivas em relação às saídas (mergulho) e às viradas por medo de sofrer algum trauma físico. Esses são movimentos que podem ser ensinados de acordo com a evolução das habilidades e nível de confiança dos praticantes de natação. Contradizendo essa ideia, Ladebeckem (1914) citado por Wilke (1990) descreveu uma adaptação ao meio líquido para iniciantes, em que saltos e saídas eram ensinados antes mesmo dos próprios estilos de nado. Porém, na prática essa sequência não é muito comum.

Em relação aos nados, o nado de costas foi o único especificamente citado. Nesse nado, o aluno não visualiza o fundo da piscina, o que aumenta sua insegurança e medo ao realizar essa posição corporal.

Estes resultados corroboram aqueles de outras modalidades que induzem o indivíduo às posições corporais fora do habitual, como a ginástica artística (DUARTE; FERREIRA FILHO; NUNOMURA, 2008; NUNOMURA; CARBINATTO; DUARTE, 2009).

Antonelli e Salvini (1978) afirmam que é possível controlar o medo por meio do treinamento específico de uma habilidade, com prevalência da dedicação e da concentração na atividade em relação ao instinto de sobrevivência. $O$ professor bem informado sobre a necessidade de cada aluno poderá intervir em cada situação de forma particular.

De acordo com o Quadro 4, sabendo que cada participante poderia descrever mais de uma forma para superar o medo, notamos que apenas uma pessoa não consegue controlar esse sentimento, e quatro praticantes não realizam o movimento que temem, o que dificulta o seu aprendizado em determinado conteúdo da natação. Nessa situação, o professor deverá ter bastante paciência com o aluno e procurar auxiliá-lo na execução do exercício, inclusive dentro d'água quando necessário.

Encontramos ainda um aluno que não pensa nesse medo e cinco praticantes que tentam executar e se concentrar no exercício. Esses normalmente apresentam um progresso maior na aprendizagem, porque tentam realizar o exercício e, muitas vezes, ao conseguir executar com sucesso "perdem" o medo. A maioria da amostra $(n=7)$ usa técnicas de respiração para se acalmar, e três se basearam em pensamentos positivos, a fim de vencer esse sentimento.

Existem vários métodos para o controle do medo, mas nem todos aqueles desenvolvidos na área clínica podem ser aplicados no esporte (BROCHADO, 2002). Para tanto, existem métodos para controlar os fatores psicológicos negativos, como o relaxamento progressivo de Jacobson (HACKFORT; SCHWENKMEZGER, 1980), o treinamento autógeno (SCHULZ, 1976), yoga e meditação. Layman (1978) confirma que a meditação transcendental (MT) é adequada para acalmar esportistas, pois diminui a hiperatividade. Sobre a MT, Hackfort e Schwenkmezger (1980) indicam que esse método reduz o medo.

Baseando-se nos resultados, observa-se que há pessoas que não conseguem manter a calma, respirar e tentar se concentrar para vencer o medo, ainda que o desejem. Fried (1999), Gervitz e Schwartz (2003) relatam que estados emocionais negativos promovem a liberação de adrenalina, que conduz a pessoa a um estado de hiperventilação e, por vezes, torna seu meio interno mais básico, e elimina grande quantidade de dióxido de carbono, o que faz precipitar contrações musculares involuntárias por todo o corpo.

Há também aqueles alunos que, ao contrário, insistem e vão superando essas barreiras 
pouco a pouco durante a aula, mas para isto é necessário que o professor planeje atividades em que o grau de complexidade aumente gradativamente.

Interessante notar que nenhum praticante mencionou que o professor de natação tentava auxiliar os alunos com seus respectivos medos. É preciso que o profissional atuante nessa área esteja inteiramente atento e disposto a ajudar o aluno a superar tal barreira e construir uma relação de confiança com o aluno (ROBINSON et al. 2004; GAYA; MARQUES; TANI, 2004).

Outra vertente que poderia diminuir o medo do praticante é a infraestrutura na qual ele se encontra para a prática da modalidade, principalmente, se esse espaço oferece segurança e conforto. No entanto, não constatamos essa criticidade nos relatos.

Está claro que um ambiente propício e bem estruturado, desde o vestiário até a piscina, poderia diminuir ou até mesmo sanar as causas de medos de alguns praticantes e envolvê-lo mais integralmente nas aulas. Piscinas com menor profundidade, raias e barras para apoio, escadas ergonômicas e pisos antiderrapantes, podem proporcionar maior sentimento de segurança ao aluno.

No Quadro 5, constatamos que a maioria dos entrevistados $(n=4)$, relatou que seu medo acontece pela falta de prática, juntamente com casos traumáticos sem influência externa. Os traumas com influência externa foram o terceiro mais relatado $(n=3)$, juntamente com casos traumáticos com família e conhecidos com influência externa. Insegurança e reportagens da mídia foram relatados por um praticante cada, ainda que a pessoa não esteja ciente que esse medo possa ter sido causado por alguém, pode ter sido causado por alguma coisa, como por exemplo, as informações da mídia.

De acordo com Santos (2003), o medo está evidente no dia-a-dia, e um motivo que o influencia é a quantidade de informações difundidas sobre os fatos da atualidade, veiculados em diversos lugares, como na televisão, nos jornais e nas revistas. Mas, também pode ter influências intrínsecas ou vivências do indivíduo sobre determinada situação.

Szpilman (2005) cita que criança e água são inseparáveis, devido ao conforto transferido do útero da mãe, e isso parece motivar a criança a buscar água durante atividades de lazer. Nessa linha de raciocínio, os traumas da infância relacionados com a água podem ter sido ocasionados por um acidente pessoal ou com alguma pessoa próxima durante alguma atividade na infância. Da mesma forma que certos acidentes nesse meio podem traumatizar a criança, também podem acontecer com o adulto, devido a brincadeiras inadequadas.

O trauma vivenciado, direta ou indiretamente, por dez sujeitos da pesquisa foi também um fator motivador para procurar a modalidade. Foram buscar a prática para superá-lo, mesmo sendo mais cômodo não se importar em ultrapassar essa barreira. Lawther (1973) explana que o sentimento de medo e informações de riscos e perigos inerentes pode aumentar a atração de alguns sujeitos. E, além disso, a escolha de determinados esportes pode reforçar a vontade de enfrentá-lo por meio da prática da atividade.

Corroborando com esse resultado, Brochado (2002) explana que as causas do medo podem ser encontradas em fatores pessoais e no meio ambiente. Seligman (1975) relata que a imprevisibilidade de acontecimentos futuros tem um papel importante no surgimento desse medo.

\section{Conclusão}

Os resultados demonstraram que vários fatores influenciam praticantes de natação a 
sentirem medo, e os fatores psicológicos negativos como insegurança, nervosismo, ansiedade e receio podem ser considerados determinantes.

Um dos movimentos que mais gera medo em praticantes de natação é a imersão, pelo fato da pessoa estar totalmente submersa e com a cabeça dentro d'água. E, muitas vezes, essa situação gera insegurança, ansiedade, e um estado de alerta ao provável "desconhecido", no caso o meio líquido, que devido às propriedades físicas da água, promove mudanças no modo de respirar e de deslocar.

Outro movimento que foi citado constantemente foi a saída (mergulho), que exige equilíbrio e coragem para se jogar, além da necessidade de um controle respiratório e deslocamento ao estar na água.

Para superar o medo, muitas pessoas realizam técnicas de respiração para se acalmar, e tentam executar o movimento específico no qual sentem medo. Porém, outras preferem não fazer o movimento por não se sentirem confiantes e isso acaba dificultando a aprendizagem e o rompimento dessa barreira do medo.

Neste contexto, o professor exerce um papel fundamental para que o aluno com medo possa desenvolver confiança, calma e persistência para a aprendizagem da natação

Finalmente, pode-se constatar que na maioria dos relatos o medo acontece pela falta de prática, associado aos casos traumáticos sem influência externa. E, nesse sentido, é preciso que o profissional utilize estratégias para que o aluno possa superar a barreira do medo.

Compreender em quais momentos da aprendizagem o sentimento de medo tem influência sobre o aluno pode indicar, aos profissionais, direcionamentos de organização e didática de aula em prol do prazer e do conforto na natação.

Assim, a relação que se estabelece entre professor/aluno e aluno/ambiente é primordial para a transposição do medo e sucesso no processo de aprendizagem na natação.

\title{
THE FEAR IN LEARNING TO SWIM
}

\begin{abstract}
The objective of this study was to investigate what causes fear in swimmers and identify what they do to overcome this feeling. The sample was composed by 18 swimming beginners, mean age was 29.72 \pm 9.70 years old. The used instrument was a questionnaire with closed and open questions. For data analysis, descriptive statistics and the "Collective Subject Discourse" (DSC) method were used. It was identified that the immersion, the diving, the lack of practice and the trauma causes fear in some students. To overcome the fear, the students perform breathing techniques and try to execute the specific movement in which they feel afraid of. Understanding the students' fears can help professionals in establishing educational directions for learning how to swim.
\end{abstract}

Keywords: Fear. Swimming. Learning.

\section{EL MIEDO EN LA ENSEÑANZA DE LA NATACIÓN}

\section{Resumen}

El objetivo de este estudio fue investigar lo que causa miedo en los practicantes de natación e identificar lo que hacen para superar este sentimiento. La muestra consistió en 18 alumnos principiantes de natación, con una media de edad fue de 29,72 \pm 9,70 años. El instrumento utilizado fue un cuestionario y para análisis de los datos fue utilizada la estadística descriptiva, y el método del "Discurso del Sujeto Colectivo" (DSC). Se identificó que la inmersión, la salida (zambullida), la falta 
de práctica, los traumas, causan miedo en algunos estudiantes. Para superar el miedo, realizan técnicas de respiración y intentan ejecutar el movimiento específico en el que sienten miedo. Comprender el miedo de los alumnos puede ayudar a los profesionales en el establecimiento de las direcciones educativas para el aprendizaje de natación.

Palabras clave: Miedo. Natación. Aprendizaje.

\section{Referências}

ANTONELLI, F.; SAVINI, A. Psicología del deporte. Valladolid: Editorial Miñon, 1978.

AINWORTH, S. O poder emocional positivo: como governar seus sentimentos. São Paulo: Cultrix, 1981.

BENTO, J. O.; TANI, G.; PRISTA, A. Desporto e Educação Física em português. Editora Universidade do Porto: Porto, 2010.

BROCHADO, M. M.V. O medo no esporte. Revista Motriz, v.8, n.2, p. 69-77, 2002.

CAVALCANTI, V.; BARBOSA, R. M. S. P. Fatores que influenciaram no aprendizado da natação por parte de envelhecentes. Boletim Informativo Unimontrisaúde em Sociogerontologia, n.2, v. 4, 2013.

COX, R.H. Sport psychology: concepts and applications. 3. ed. Dubuque: WCB Brown \& Benchmark, 1994.

DAMÁSIO, A. R. O erro de Descartes: emoção, razão, e o cérebro humano. São Paulo: Companhia das Letras, 1996.

DUARTE, L. H.; FERREIRA FILHO, R. A.; NUNOMURA, M. Medo na ginástica artística: treinamento e competição. Revista Mackenzie de Educação Física e Esporte, v.07, 2008. p.51-67.

EKMAN, P. Emotions revealed. Understanding faces and feelings. London: Phoenix, 2004.

FENLEY, D.A. Coping with fear in high level gymnastics. In: SALMELA, J.H.; PETIOT, B; HOSHIZAKI, T.B. Psychological nurturing and guidance of gymnastic talent. Montreal: Sport Psyche Editions, 1987.

FERNANDES, J. R. P.; COSTA, P. H. L. Pedagogia da natação: um mergulho para além dos quatro estilos. Revista brasileira de Educação Física e Esporte. São Paulo, v. 20, n.1, p. 514, jan./mar, 2006.

FISCHER, F. et al. Estados emocionais e Educação Física escolar: considerações iniciais à luz de uma psicologia bioecológica. Coleção Pesquisa em Educação Física, v. 8, n. 2, 2009. p. 89-96. 
FRIED, R. Relaxation with biofeedback-assisted guided imagery: the importance of breathing rate as an index of hypoarousal. Applied Psychophysiology and Biofeedback, v. 12, n. 4, p. 273-279, 1987.

GALDI, E. H. G. et. al. Aprender a nadar com a extensão universitária. Campinas, SP: IPES Editorial, 2004.

GAYA, A.; MARQUES, A.; TANI, G (Org.). Desporto para crianças e jovens: razões e finalidades. Editora UFRGS: Porto Alegre, 2004.

GERVITZ, R. N., SCHWARTZ, M. S. The respiratory system in applied psychophysiology. In: SCHWARTZ, M. S.; ANDRASIK, F. (Ed.) Biofeedback: a practtioners guide. 3. ed. New York: The Guilford Press, p. 212-44, 2003.

GRAHAM, J.; GAFFAN, E. A. Fear of water in children and adults: etiology and familialeffects. Revista Behaviour Research and Therapy,v. 35, p. 91-108, 1997.

HACKFORT, D.; SCHWENKMEZGER, P. Angst und angstkontrolleim sport. Köln: Psychologisches Institut der Deutschen Sporthochschule, 1980.

HOLANDA, V. N. et al. As bases biológicas do medo: uma revisão sistemática da literatura. Revista Interfaces: saúde, humanas e tecnologia, ano 1, v. 1, n.3, set. 2013.

HONGLER, R. El stress y el miedo em deporte. Revista de Entrenamiento Desportivo, v. 2, n.4, p. 20-31, 1988.

HUBER, A. El miedo. Madri: Acento Editorial, 2000.

LAYMAN, E. Meditation and sports performance. In: STRAUB, W.F. (Ed.).Sport psychology: an analysis of athlete behavior. New York: Mouvement Publications, p. 169-176, 1978.

LEFÈVRE, F; LEFÈVRE A. M. C. O Discurso do Sujeito Coletivo. Um novo enfoque em pesquisa qualitativa - desdobramentos. Caxias do Sul: Educs, 2003.

LENT, R. Cem bilhões de neurônios: conceitos fundamentais da neurociência. São Paulo: Atheneu, 2001.

MAGYAR, T.M.; CHASE, M.A. Psychological strategies used by competitive gymnasts to overcome the fear injury. Technique, v.16, n.10, 1996.

MINEIRO, A. et al. Objetivos dos alunos ao se matricularem em academias de natação na região metropolitana de Santos. FIEP Bulletin On-line, v.83, 2013. Disponível em: <http://www.fiepbulletin.net/index.php/fiepbulletin/article/view/2955>. Acesso em: 27 jul. 2015. 
MIRA Y LÓPEZ, E. Quatro gigantes da alma: o medo, a ira, o amor e o dever. Traduzido por Cláudio de Araújo Lins. Rio de Janeiro: José Olympo, 1991.

MORRIS, R.J.; KRATOCHWILL, T.R. Treating children's fears and phobias. New York: Pergamon Press, 1983.

NISTA-PICCOLO, V.L.; NUNOMURA, M. Os Jogos Olímpicos na perspectiva da pedagogia do esporte no Brasil. In, MOREIRA, W.W; BENTO, J.O (Org.). Citius, Altius e Fortius. Casa da Educação Física: Belo Horizonte, p. 171-208, 2014.

NUNOMURA, M.; CARBINATTO, M. V.; DUARTE, H. Vencendo o medo na ginástica artística. Arquivos em movimento, Rio de Janeiro, v. 5, n. 2, jul./dez., 2009.

PARKER, H.E.; BLANKSBY, B.A. Starting age and aquatic skill learning in youngchildren: mastery of prerequisite water confidence and basic aquatic locomotion skills.Australian Journal of Science and Medicine in Sport,v. 29, n. 3, p. 83-90, 1997.

POULTON, R. et al. Water trauma and swimming experiences up to age 9 and fear of waterat age 18: a longitudinal study. Behaviour Research and Therapy.v. 37, n. 39-48, 1999.

RESSURREIÇÃO, K. S. et al. Manifestações emocionais de crianças com Síndrome de Down na natação. Revista Mackenzie de Educação Física e Esporte, v.7, n.3, 2008.

ROBINSON, E.H.; ROTTER, J.C.; ROBINSON, S.L.; FEY, M.A; VOGEL, J.E. Fears, Stress and trauma: helping children cope. Greensboro: CAPS Press, 2004.

SANTOS, L. O. O medo contemporâneo: abordando suas diferentes dimensões. Revista de Psicologia: Ciência e Profissão, v. 23, n. 2, jun., 2003.

SCHULZ, J. H. Das autogene training: konzentrative entspannung. Stuttgart: Thieme, 1976.

SELIGMAN, M. E. P. Helplessness. San Francisco: Freeman, 1975.

SZPILMAN, D. Afogamento na infância: epidemiologia, tratamento e prevenção. Revista Paulista de Pediatria, v. 3, n. 23, 2005. p.142-53.

TANI, G.; BENTO, J.O.; PETERSEN, R.D. de S. Pedagogia do desporto. Guanabara Koogan, Rio de Janeiro, 2006.

THOMAS, A. Esporte: introdução à psicologia. Rio de Janeiro: Ao Livro Técnico, 1983.

VELASCO, C. G. Natação segundo a psicomotricidade. Rio de Janeiro: Sprint, 1997.

WEISS, M.R. et al. Observationallearning and the fearful child: influence of peer models on swimming skill performance andpsychological responses. Research Quarterly for Exercise 
and Sport. v. 69, n. 4, p. 380-94, 1998.

WILKE, K. Anfängerschwimmen. Reinbek Bei. Hamburg: Rowohlt Taschenbuch Verlag, 1990.

Recebido em: 29/07/2014

Revisado em: 17/05/2015

Aprovado em: 01/09/2015

Endereço para correspondência:

alinedessupoio@bol.com.br

Aline Dessupoio Chaves

Universidade Federal do Triângulo Mineiro, Departamento de Educação Física. Av. Getúlio Guaritá, 130/313

Abadia

38025-180 - Uberaba, MG - Brasil 